\title{
Epidemiology of CoViD-19 Pandemic: Recovery and mortality ratio around the globe
}

\author{
Aziz Ullah Noor ${ }^{1}$, Farhana Maqbool², \\ Zulfiqar A. Bhatti ${ }^{3}$, Asmat Ullah Khan ${ }^{4}$
}

\begin{abstract}
SUMMARY
Coronavirus Disease 2019 (CoViD-19) is the third type of coronavirus disease after severe acute respiratory syndrome (SARS) and Middle East respiratory syndrome (MERS) that appears in human population from the past two decades. It is highly contagious and rapidly spread in the human population and compelled global public health institutions on high alert. Due to genetic similarity of this novel coronavirus 2019 with bat virus its emergence from bat to humans is possible. The virus survive in the droplets of coughing and sneezing and spread around the large areas through infected person resulting in its rapid spread among people. Clinical symptoms of CoViD-19 include fever, dry cough, dyspnea, loose stool, nausea and vomiting. The present review discuss the origin of CoViD-19, its rapid spread, mortality rate and recoveries ratio around the world. Since its origin from Wuhan, the CoViD-19 spread very rapidly all across the countries, on April 17, 2020 this disease has affected 210 countries of the globe. The data obtained showed over 2.4 million confirmed cases of CoViD-19. Higher mortality rate was found in Algeria and Belgium as $15 \%$ and $13.95 \%$, respectively. Lower mortality rate was found in Qatar $0.17 \%$ and Singapore $0.2 \%$. Recovery versus deceased ratio showed that recovery was 68, 59 and 35 times higher than the death in Singapore, Qatar and Thailand respectively. It is concluded that 2019-novel corona virus is a zoonotic pathogen similar to MERS and SARS. Therefore, a barrier should be maintained between and across the human, household and wild animals to avoid such pandemics.
\end{abstract}

KEYWORDS: CoViD-19, Pandemic, Public health, Wuhan, Zoonotic.

doi: https://doi.org/10.12669/pjms.36.COVID19-S4.2660

How to cite this:

Noor AU, Maqbool F, Bhatti ZA, Khan AU. Epidemiology of CoViD-19 Pandemic: Recovery and mortality ratio around the globe. Pak J Med Sci. 2020;36(COVID19-S4):COVID19-S79-S84. doi: https://doi.org/10.12669/pjms.36.COVID19-S4.2660

This is an Open Access article distributed under the terms of the Creative Commons Attribution License (http://creativecommons.org/licenses/by/3.0), which permits unrestricted use, distribution, and reproduction in any medium, provided the original work is properly cited.

1. Aziz Ullah Noor,

2. Farhana Maqbool, Ph.D.

3. Zulfiqar A. Bhatti, Ph.D.

Department of Environmental Science,

COMSATS University, Abbottabad Campus, 22060 Pakistan

4. Asmat Ullah Khan,

Department of Human Anatomy,

Southern Medical University, Guangzhou, P. R. China.

1,2: Department of Microbiology, Faculty of Health Sciences,

Hazara University, Mansehra,

Khyber Pakhtunkhwa, Pakistan.

Correspondence:

Dr. Farhana Maqbool,

Assistant Professor,

Department of Microbiology, Faculty of Health Sciences,

Hazara University, Mansehra,

Khyber Pakhtunkhwa, Pakistan.

Email: drfarhana@hu.edu.pk

* Received for Publication:

April 11, 2020

* $1^{\text {st }}$ Revision Received:

* $\quad 2^{\text {nd }}$ Revision Received:

April 20, 2020

April 25, 2020

* Final Revision Accepted:

April 27, 2020

\section{INTRODUCTION}

Coronaviruses (CoVs) are extremely important, widely distributed pathogens found in both humans and mammals. These are enveloped, single-stranded RNA viruses belonging to family Coronaviridae, circulating in birds and mammals and affecting human, domestic and wild animals. ${ }^{1}$ Two coronaviruses related human diseases emerged previously in 2003 and 2012, have been named as SARS and MERS respectively. These two strains of corona viruses collectively affected 10,000 people with a fatality rate of $10 \%$ for SARS$\mathrm{CoV}$ and $37 \%$ for MERS-CoV. ${ }^{2,3}$

During the last 50 years, the emergence and re-emergence of deadly infectious diseases have increased. SARS-CoV-1 disease was originated in 
Guangzhou city of China and the start of 2020 was again a challenging year for this country because of extremely contagion 2019-novel coronavirus (2019-nCoV) disease outbreak. ${ }^{4}$ This virus is also known as SARS-CoV-2 because of its same place of origin and genetic similarity with slight mutation in SARS-CoV-1 strain.

In December, 2019 a series of new cases of pneumonia were reported in Wuhan, China, whose clinical presentation were resembled to viral pneumonia. ${ }^{5}$ Deep sequencing helped to diagnose the new virus, named as 2019 novel coronavirus (2019-nCoV) by World Health Organization (WHO). The origin of this virus has been reported in Wuhan, China. Few recent reports suggested its transmission from animal to human and within humans, which signifies its zoonotic potential. ${ }^{6}$ So far, over 2.4 million cases have been reported worldwide with a total fatality reached to over two lac till April 26, 2020. The virus has been reported from many other countries mainly due to the traveling of infected/suspected people from China to these countries. Chinese health ministry took immediate action to investigate and control the disease, including quarantine measures, continuous observation of contacts, clinical and epidemiological data collection from infected people and development of diagnostic tools and efficient treatment protocols. Beside these measures Chinese government had recommended to immigrant not to travel back to home country and should stay in 14 days quarantine before leaving to stop its further spread but many countries have not paid attention on this advice as a result coronavirus spread globally. This review focuses on origin of 2019-nCoV, incidence of CoViD-19 in China, its clinical manifestations, mortality and recovery around the globe.

\section{Origin of 2019-novel corona virus}

The source of origin of coronavirus is still a mystery, however, early investigations have reported its possible origin from the Wuhan Seafood Wholesale Market. Most of the early patient history associated with their movement to that Seafood Market. Whereas, there were numerous other patients who have not gone to that market in those days. That association indicated its human to human transmission in spreading the outbreak. Few environmental samples taken from the market have been reported positive but no specific animal was identified as its origin. ${ }^{7}$ An initial investigation based on codon claimed snake as an origin. ${ }^{8}$ It has also been proposed, that
2019-nCoV naturally propagates in bats. ${ }^{9}$ Previous study revealed that wet markets of southern China including Wuhan and Guangzhou cities have the greater risk of spreading novel corona viruses, because of wild animal trading and the absence of biosecurity measures. ${ }^{10}$ The other possibility is that bats and their excrements are commonly used in Traditional Chinese Medicine, which may also be a source of infection. ${ }^{11}$ It is also possible that the virus had infected other mammal that was traded at the market and served as the source of the infection to people.

Two already highly pathogenic coronaviruses were reported to be originated from the animals. The transmission of the first highly pathogenic virus, SARS-CoV occurred from animal to human in Wet markets. The source of SARS-CoV was bat which transferred this virus to human via civet cat as an intermediate host. ${ }^{12}$ The bats were also reported to be the possible origin of MERS-CoV, which is also a zoonotic virus. ${ }^{13}$ However, MERS$\mathrm{CoV}$ was reported in the patients, having frequent contact with the camels in the Middle East. Dromedary Camel was considered as traditional household animal, to avoid contact with camel is not possible due to which they suffered from the periodic outbreak of MERS-CoV. ${ }^{14}$ In this context, the identification of source animals, responsible for the transmission of CoViD-19 virus is extremely essential in order to control and prevent any future outbreak. The possible transmission cycle of CoViD-19 is presented in Fig.1.

\section{Current Outbreak of CoViD-19 in China}

CoViD-19 is a great public health and safety concern all across the globe and the Chinese government, international agencies and $\mathrm{WHO}$ is aware of the consequences of the outbreak. The first case of CoViD-19 outside China was reported in Thailand. ${ }^{15}$

Due to rise in infected and suspected cases of CoViD-19 in China by the end of the third week of January 2020, the Chinese government had completely lockdown the Wuhan city, Hubei province. They partially lockdown other cities at higher risk to stop its further spreading. Since the public health emergency declared by WHO, much more attention at national and international levels has been focused on CoViD-19. The concept of One Health which means that 'the health of people is linked with the animal and connected environment' has gained great importance in this current scenario. ${ }^{16,17}$ 


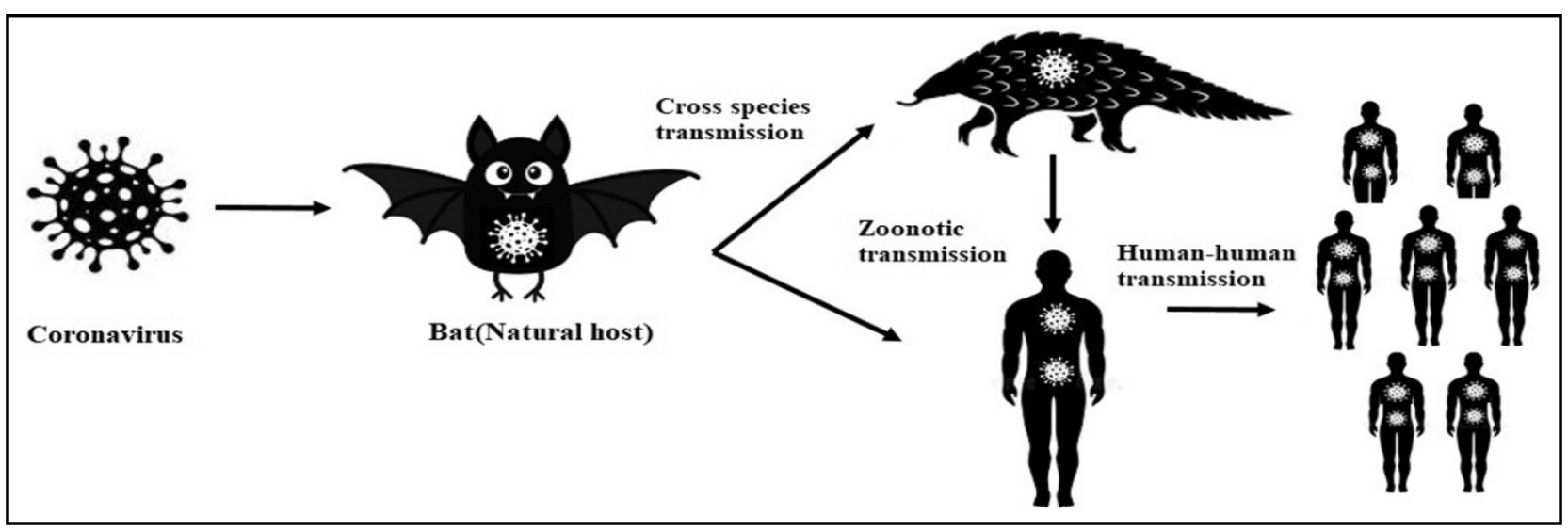

Fig.1: Transmission flow chart of CoViD-19.

The super-spreaders (infected person who travels and infect others) are mostly responsible for large outbreaks. For example, traveling of one infected person with SARS-CoV from Hong Kong to Toronto infected 128 people in a local health care facility where he visited for treatment. The same situation was with MERS-CoV, where a single patient from Saudi Arabia traveled to South Korea infected 186 patients with MERS-CoV. ${ }^{18}$

The epidemiological characteristics observed in the case of CoViD-19 varied to a great extent as compared to the SARS-CoV. The 2019-nCoV replicates efficiently in the upper respiratory tract, but the onset of symptoms appears to be slow. Although the infected individual carries a huge number of virus still he/she can perform his/her normal activities, which leads to the spread of this infection to other individuals. Whereas, in the SARS-CoV patients, the transmission of infection is not reported during the prodromal period and transmission occurs when the patient becomes severely ill. ${ }^{7}$

Various factors affect and determine the spread of disease in an outbreak including transmissibility and severity. Morbidity and mortality will rely on the combination of transmissibility and severity and a rapid person to person transmission occurred in this outbreak. The epidemiologists estimated the $R_{\mathrm{O}}$ (the basic reproduction number to measure the transmissibility) value would be 2.2 for CoViD-19. ${ }^{19}$

The severity and the case-fatality rate could be underestimated because many infected people have not yet recovered and may deceased.

Vertical transmission of CoViD-19

After the onset of the CoViD-19 outbreak, the potential risk of vertical transmission was a question mark. Control and prevention of this novel emerging infection among pregnant women have become a primary concern regarding vertical transmissibility. The latest study published in The Lancet gives some insight into the clinical features during pregnancy and potential of vertical transmission CoViD-19 infection in pregnant women. ${ }^{20}$ Although the research manipulates only a small number of nine pregnant women with confirmed CoViD-2019, no evidence for intrauterine infection was reported in late pregnancy in these cases. ${ }^{21}$

A SARS-CoV-2 genomic study suggested that this virus has $88 \%$ genetic similarity with two SARS-like coronaviruses isolated from a bat, SbatSL-CoVZC45 and bat- SL-CoVZXC21. While in case of SARS-CoV-1 and MERS-CoV bat's genome similarities were $79 \%$ and $50 \%$ respectively. Homology studies have shown that SARS-CoV-2 has a similar receptor binding structure to that of SARS-CoV-1. So, the ability of vertical transmission of corona-19 could be as low as that of SARSCoV- $1 .{ }^{22}$

Although 2019-nCoV has adverse effects on newborn including shortening of breathing, premature birth and liver disorder but its vertical transmission has not proved. ${ }^{23}$ The clinical findings of CoViD-19 infected pregnant women were same as non-pregnant women infected with CoViD-19 infection. ${ }^{24}$

\section{Clinical manifestations}

In accordance with SARS-CoV and MERS CoV, this new virus was observed to affect more males than female individuals. The reduced susceptibility of women can be explained by the fact that the sex hormone and $\mathrm{X}$ chromosome play an important role in innate and adaptive immunity. Moreover, almost half of the population infected by CoViD-19 has underlying problems mainly diabetes, 
cerebrovascular and cardiovascular problems similar to MERS-CoV. The older people with the weak or compromised immune system are more susceptible to this disease. ${ }^{24}$

Among the clinical signs; fever, dry cough, dyspnea, and fatigue were common in all cases. Upper respiratory tract infection i.e. rhinorrhea, sneezing, or sore throat were also uncommon in CoViD-19. The laboratory reports of CoViD-19 patients indicates lymphopenia (decrease in white blood cells) which suggested the destruction of lymphocyte and other immune cells by coronavirus leading to the weakening of cellular immune system..$^{25}$ Some patients suffer from acute respiratory distress and septic shock which lead to the failure of multiple organs. ${ }^{24-26}$ These cases are of crucial importance to be treated at earlier stages. CT scan indicated ground-glass opacification and occasional consolidation in the patients. ${ }^{27}$

Most of the deaths have been reported in the patients who have the characteristic of warning signs described by the Multi Logistic Binary Search Tree analysis (MuLBSTA) model. These six signs which are included in the MuLBSTA model are multinodular infiltration, lymphopenia, bacterial co-infection, smoking history, hypertension and age. ${ }^{28}$

\section{Treatment and prevention}

Few or no options are available for treating a viral disease that emerged suddenly, no vaccine has been developed yet for the prevention of CoViD-19 infection. ${ }^{26}$ A combination of antiviral drugs Lopinavir/Ritonavir, PEGylated interferon, and ribavirin has been used in a MERS-CoV case reported in South Korea, that helped in the successful clearance of the virus. ${ }^{29}$ Another viral drug, remdesivir has been reported to be effective against the viral infection. In-vitro studies indicated that Remdesivir has been successful in the termination of viral RNA replication, ${ }^{30,32}$ and showed effectiveness against the MERS-CoV, SARS$\mathrm{CoV}$ and other bat originated coronaviruses. ${ }^{31,33}$

Qamar et al., 2020 screened the database of 32,297 Chinese medicinal plants for their antiviral activity. They suggested 9 medicinal plants that might help in the prevention of viral replication. ${ }^{34}$ Further studies are necessary to figure out the effectiveness of these plants in this infection. Another study on virtual screening of a database of more than 3000 Food and Drug Administration (FDA) approved drugs was carried out in order to find the possible best available drug. The results suggested that protein inhibitors in Human
Immunodeficiency Virus (HIV) drugs might be helpful against the CoViD-19. ${ }^{35}$ Recently FDA have authorized the use of hydroxychloroquine and chloroquine due to emergency situation without double blind and clinical trial for the treatment of CoViD-19. ${ }^{36}$

Mortality and recovery ratio around the globe

Since the discovery of the virus, the CoViD-19 spread very rapidly all across the countries and cases have been reported in 210 countries around the globe (till 10:39 GMT on April 26, 2020). The data obtained showed over 2.4 million confirmed cases of CoViD-19. ${ }^{37}$ Higher mortality rate $(15 \%)$ was found in Algeria, Belgium (13.95), Italy and United Kingdom (13\%) and Netherland (11.35\%). Lower mortality rate was found in countries Qatar $0.17 \%$, Singapore $0.2 \%$, United Arab Emirate $0.6 \%$, and Australia 0.97. The WHO keeps on updating and sharing these figures on daily basis and till April $28^{\text {th }}$ it had iussued ninety seven reports giving countrywise details of number of cases.

Higher mortality rate is related with the total number of infected cases, as significant positive correlation $\mathrm{r}=0.9, \mathrm{n}=56$ was found between confirmed cases and deaths, which showed that disease spread increases the risk of death due to overcrowded hospitals, lower availability of medical facility and other environmental factors. Before mitigation measures were taken place CoViD-19 was already spread in the early stages..$^{38}$ Countries showed early response suffered less than the countries that did not care in the early stage of this pandemic. Yet another reason of this pandemic was as $80 \%$ of CoViD-19 cases are mild or asymptomatic so the symptom base control of this disease is very difficult and less effective.

Recovery versus deceased ratio was calculated and the data showed that recovery was 68, 59 and 35 times higher than the death in Singapore, Qatar and Thailand respectively. Lower value of deceased over recovery ratio was found in United Kingdom (0.03), Netherland (0.08), Ireland (0.16) and Norway (0.21). ${ }^{37}$ In contrast to CoViD-19 prevalence, previous study shows that community acquired pneumonia cases were high in male who belonged to lower socio-economic group, illiterate people living in rural areas. ${ }^{39}$ Patients recoveries are significantly correlated with the number of cases $(r=0.63, n=56)$, showed that recoveries are increasing with increase in number of cases. The potential factors involved in the recovery might be strong immune system among the population, good dietry habits and early treatment and Bacillus 
Calmette-Guérin (BCG) vaccination policy in some country showed less cases than without BCG vaccinated nations. ${ }^{40}$

According to Reuter the Global death due to COVID19 disease passed two hundred thousand on April $25^{\text {th }} 2020$ and it is expected that the total number of infected cases will cross three million people by the end of April 2020. More than 50\% of these deaths have occurred in United States, Spain and Italy the worst hit countries. Till April $25^{\text {th }}$ United States had reported fifty two thousand four hundred deaths while Italy, Spain and France have reported between 22,000 and 26,000 fatalities each. Of the top twenty most severely affected countires Belgium has reported highest number of fatalities per capita with six deaths per ten thousand people compared to 4.9 in Spain and 1.6 in the United States. The overall mortality rate of cases reported in United States has been $8 \%$ while more than $10 \%$ cases reported in Spain and Italy have resulted in Deaths. Asia and Latin America have each reported more than seven thousand deaths while Middle East has reported more than eight thousand eight hundred deaths. ${ }^{41}$

\section{CONCLUSION}

The danger of CoViD-19 can be argued by the fact that this virus has inherited the ability to mutate. It is accepted that most viruses survived in their natural reservoir for a longer time. Therefore, the most fruitful method to prevent viral zoonosis is to preserve the barriers between human society and natural reservoir of viruses. Global preparedness for any outbreak has been suggested that national health security plan is alarmingly weak around the world and we should prepare ourselves better for the future.

Acknowledgment: We would like to thanks to Dr. Mudassar Mohiuddin for his editing and final review.

Conflicts of interest: None.

Grant Support \& Financial Disclosures: None.

\section{REFERENCES}

1. Miłek J, Blicharz DK. Coronaviruses in avian species. Review with focus on epidemiology and diagnosis in wild birds. J Vet Res. 2018;62(3):249-255. doi:10.2478/ jvetres-2018-0035.

2. WHO. Summary of probable SARS cases with onset of illness from 1 November 2002 to 31 July 2003. [cited April 4, 2020]. Available from: https://www.who.int/csr/sars/ country/table2004_04_21/en/.
3. WHO. Middle East respiratory syndrome coronavirus (MERS-CoV). 2019. [cited April 2, 2020]. Available from: http://www.who.int/emergencies/mers-cov/en/.

4. Zhu N, Zhang D, Wang W, Li X, Yang B, Song J, et al. A novel Coronavirus from patients with pneumonia in China 2019. N Engl J Med. 2020;382:727-733.

5. WHO. Pneumonia of unknown cause - China. [cited April 3, 2020]. Available from: https://www.who.int/ csr/don/05-january-2020-pneumonia-of-unkown-causechina/en/.

6. Chan JFW, Yuan S, Kok KH, To KKW, Chu H, Yang $\mathrm{J}$, et al. A familial cluster of pneumonia associated with the 2019 novel coronavirus indicating person-toperson transmission: A study of a family cluster. Lancet. 2020;395(10223):514-523.

7. WHO. Novel Coronavirus -Japan (ex-China). [cited April 2020] Available from: https://www.who.int/csr/don/16january-2020-novel-coronavirus-japan-ex-china/en/.

8. Ji W, Wang W, Zhao X, Zai J, Li X. Homologous recombination within the spike glycoprotein of the newly identified coronavirus may boost cross-species transmission from snake to human. J Med Virol. 2020; 92(4). doi:10.1002/jmv.25682.

9. Robertson DL. nCoV's relationship to bat coronaviruses. [cited April 4, 2020]. Available from: http://virological. org/t/ncovs-relationship-to-bat-coronavirusesrecombination-signals-no-snakes-no-evidence-the-2019ncov-lineage-is-recombinant/331

10. Cheng VC, Lau SK, Woo PC, Yuen KY. Severe acute respiratory syndrome coronavirus as an agent of emerging and reemerging infection. Clin Microbiol Rev. 2007;20(4):660-694. doi: 10.1128/CMR.00023-07

11. Riccucci M. Bats as materia medica: An ethnomedical review and implications for conservation. Vespertilio. 2013;16:249-270.

12. Fong IW. Emerging Animal Coronaviruses: First SARS and now MERS. In: Emerging infectious diseases of the 21st Century, Springer, Cham. 2017;63-80.

13. Lau SK, Woo PC, Li KS, Huang Y, Tsoi HW, Wong BH, et al. Severe acute respiratory syndrome coronaviruslike virus in Chinese horseshoe bats. Proc Natl Acad Sci. 2005;102(39):14040-14045.

14. Azhar EI, Elkafrawy SA, Farraj SA, Hassan AM, Alsaeed MS, Hashem AM, et al. Evidence for camel-to-human transmission of MERS coronavirus. New Engl J Med. 2014;370(26):2499-2505.

15. Sookaromdee $\mathrm{P}$, Wiwanitkit V. Imported cases of 2019-novel coronavirus (2019-nCoV) infections in Thailand: Mathematical modelling of the outbreak. Asian Pac J Trop Med. 2020;13(3): 139-140.

16. Hui DS, Azhar EI, Madani TA, Ntoumi F, Kock R, Dar O, et al. The continuing 2019-nCoV epidemic threat of novel coronaviruses to global health-The latest 2019 novel coronavirus outbreak in Wuhan, China. Int J Infect Dis. 2020;91:264-266.

17. Heymann DL. Data sharing and outbreaks: Best practice exemplified. Lancet. 2020;395(10223):469-470.

18. De-Wit E, Van-Doremalen N, Falzarano D, Munster VJ. SARS and MERS: recent insights into emerging coronaviruses. Nat Rev Microbiol. 2016;14(8):523-534.

19. Wang D, Hu B, Hu C, Zhu F, Liu X, Zhang J, et al. Clinical characteristics of 138 hospitalized patients with 2019 novel coronavirus-infected pneumonia in Wuhan, China. J Amer Med Associ. 2020;323(11):1061-1069.

20. Wang C, Horby PW, Hayden FG, Gao GF. A novel coronavirus outbreak of global health concern. Lancet. 2020;395(10223):470-473. 
21. Chen H, Guo J, Wang C, Luo F, Yu X, Zhang W, et al. Clinical characteristics and intrauterine vertical transmission potential of COVID-19 infection in nine pregnant women: A retrospective review of medical records. Lancet. 2020;395(10226):809-815.

22. Lu R, Zhao X, Li J, Niu P, Yang B, Wu H, et al. Genomic characterisation and epidemiology of 2019 novel coronavirus: Implications for virus origins and receptor binding. Lancet. 2020;395(10224):565-574.

23. Zhu H, Wang L, Fang C, Peng S, Zhang L, Chang G, Xia S, Zhou W. Clinical analysis of 10 neonates born to mothers with 2019-nCoV pneumonia. Transl Pediatr. 2020;9(1):5160. http://dx.doi.org/10.21037/tp.2020.02.06.

24. Chen N, Zhou M, Dong X, Qu J, Gong F, Han Y, et al. Epidemiological and clinical characteristics of 99 cases of 2019 novel coronavirus pneumonia in Wuhan, China: a descriptive study. Lancet. 2020;395(10223):507-513.

25. Liu WJ, Zhao M, Liu K, Xu K, Wong G, Tan W, et al. T-cell immunity of SARS-CoV: Implications for vaccine development against MERS-CoV. Antiviral Res. 2017;137:82-92.

26. Huang C, Wang Y, Li X, Ren L, Zhao J, Hu Y, et al. Clinical features of patients infected with 2019 novel coronavirus in Wuhan, China. Lancet. 2020;395(10223):497-506.

27. Ng MY, Lee EY, Yang J, Yang F, Li X, Wang H, et al. Imaging profile of the COVID-19 infection: Radiologic findings and literature review. Radiology: Cardiothoracic Imaging. 2020;2(1). https:// doi.org/10.1148/ryct.2020200034.

28. Guo L, Wei D, Wu Y, Zhou M, Zhang X, Li Q, et al. Clinical features predicting mortality risk in patients with viral pneumonia: the MuLBSTA score. Front Microbiol 2019;10:2752. doi.org/10.3389/fmicb.2019.02752.

29. Kim UJ, Won EJ, Kee SJ, Jung SI, Jang HC. Case report Combination therapy with lopinavir/ritonavir, ribavirin and interferon- $a$ for Middle East respiratory syndrome. Antiviral Ther. 2016;21:455-459. doi: 10.3851/IMP3002

30. Warren TK, Jordan R, Lo MK, Ray AS, Mackman RL, Soloveva $\mathrm{V}$, et al. Therapeutic efficacy of the small molecule GS-5734 against Ebola virus in rhesus monkeys. Nature. 2016;531(7594):381-385.

31. Jordan PC, Liu C, Raynaud P, Lo MK, Spiropoulou CF, Symons JA, et al. Initiation, extension, and termination of RNA synthesis by a paramyxovirus polymerase. PLoS Pathog. 2018;14(2). doi: 10.1371/journal.ppat.1006889. eCollection 2018 Feb.

32. Cockrell AS, Yount BL, Scobey T, Jensen K, Douglas M, Beall A, et al. A mouse model for MERS coronavirusinduced acute respiratory distress syndrome. Nat Microbiol. 2016;2:16226. doi: 10.1038/nmicrobiol.2016.226
33. Brown AJ, Won JJ, Graham RL, Dinnon III KH, Sims AC, Feng JY, et al. Broad spectrum antiviral remdesivir inhibits human endemic and zoonotic deltacoronaviruses with a highly divergent RNA dependent RNA polymerase. Antiviral Res. 2019;169:104541. doi: 10.1016/j. antiviral.2019.104541. Epub 2019 Jun 21.

34. Qamar MT, Alqahtani SM, Alamri MA, Chen LL. Structural basis of SARS-CoV-2 3CLpro and anti-COVID-19 drug discovery from medicinal plants. J Pharm Anal. 2020;Preprint. doi: 10.1016/j.jpha.2020.03.009

35. Contini A. Virtual screening of an FDA approved drugs database on two COVID-19 coronavirus proteins. 2020. Chem Rxiv. Preprint. doi: 10.26434/chemrxiv.11847381.v1

36. Jaffe S. Regulators split on antimalarials for COVID-19. The Lancet World Report. 2020;395(10231):1179. doi: 10.1016/ S0140-6736(20)30817-5

37. Worldometer, COVID-19 coronavirus pandemic. [cited April 17, 2020]. Available from: https://www. worldometers.info/coronavirus/\#countries..

38. Anderson RM, Heesterbeek H, Klinkenberg D, Hollingsworth TD. How will country-based mitigation measures influence the course of the COVID-19 epidemic? Lancet 2020;395 (10228):931-934. doi: 10.1016/S01406736(20)30567-5.

39. Malik AS, Khan MI. Profiles of community acquired pneumonia cases admitted to a Tertiary Care Hospital. Pak J Med Sci. 2012;28(1):75-78.

40. Miller A, Reandelar MJ, Fasciglione K, Roumenova V, Li Y, Otazu GH. Correlation between universal BCG vaccination policy and reduced morbidity and mortality for COVID-19: an epidemiological study. Br Med J. 2020; Preprint doi: 10.1101/2020.03.24.20042937.

41. Global Corona virus death toll hits two hundred thousand. Daily Dawn April26th 2020. Page-1.

\section{Author`s Contribution:}

AUN: Collection of basic information.

FM: Review writing and editing.

ZAB: Updated data collection and organization, helped in writing.

AUK: Helped in writing and performed statistical analysis. 